\title{
Über den Aufbau des Wörterbuchs der geflügelten Worte der modernen deutschen Schriftsprache (für Belarussen, die Deutsch als Fremdsprache studieren oder lernen)
}

\begin{abstract}
Annotation
Der Artikel ist der Beschreibung der Wörterbuchstruktur der gebräuchlichen geflügelten Worte in der modernen deutschen Schriftsprache gewidmet. Dieses Wörterbuch richtet sich an Belarussen, die Deutsch als Fremdsprache studieren oder lernen. Die vorliegende Arbeit liefert Textquellen der geflügelten Worte in der deutschen Sprache, die Prinzipien des Aufbaus des Wörterbuchs, seinen Umfang, die Struktur des Wörterbuchartikels und auch die Beispiele der lexikografischen Beschreibung von geflügelten Worten aus deutschen Quellen. Zu jedem deutschen geflügelten Wort im Wörterbuch kann ein Äquivalent in der belarussischen Sprache zugewiesen werden. Daher könnte das Wörterbuch auch von Deutschsprachigen, die die belarussische Sprache studieren oder lernen, als Übersetzungswörterbuch eingesetzt werden.
\end{abstract}

Schlüsselwörter: die moderne deutsche Sprache, die moderne belarussische Sprache, geflügelte Worte, Textquellen, das Wörterbuch

\section{Einleitung}

Sprachlerner, die über das Wissen und die Fähigkeit verfügen, mehrere verschiedene und im Verhältnis zueinander diverse Sprachen zu verwenden, nutzen eine breite Palette von Redewendungen, die aus verschiedenen Textquellen, einschließlich fremdsprachiger Quel- 
len stammen. Solche Ausdrücke werden als ,geflügelt“ bezeichnet und bilden das Thema der gleichnamigen, weltberühmten Publikation des deutschen Philologen und Lexikografen Georg Büchmann (1822-1884), dessen Wörterbuch „Geflügelte Worte“ im Jahr 1864 veröffentlicht worden ist und seitdem über 30-mal nachgedruckt war. Zu den von G. Büchmann hervorgehobenen Hauptmerkmalen der geflügelten Worte gehören eine dauernde Anführung in der Sprache und ein nachweisbarer Ursprung - das Vorhandensein eines historischen Urhebers oder einer literarischen Ursprungsquelle (Büchmann, 1972: XV).

Die geflügelten Worte bilden eine der ausdrucksstärksten Schichten der nationalen Phraseologie, ein Mittel der bildhaften und ausdrucksvollen Schriftsprache. In jeder Sprache bilden sie ein sehr verschiedenartiges Objekt, das aus einer großen Anzahl von Einheiten besteht, die sich nicht nur in ihrer sprachlichen und kulturellen Herkunft, sondern auch in ihren Textquellen, grammatischer Struktur, Semantik, Funktionsweise usw. unterscheiden. Das Vorhandensein von geflügelten Worten, ihre Anzahl und Gebräuchlichkeit sowie die Möglichkeit, aufgrund von Texten der eigenen Nationalliteratur zu extrapolieren, sind wichtige Merkmale für den Entwicklungsstand jeder Schriftsprache.

In der ostslawischen Sprachwissenschaft hat sich Ende des 20. - Anfang des 21. Jahrhunderts eine anfängliche Vorstellung von geflügelten Worten als sprachlichen Einheiten herausgebildet. Die geflügelten Worte sind weithin bekannte und oft verwendete Zitate aus verschiedenen Textquellen (Дядечко/Djadechko, 2002; Шулежкова/Shulezhkova, 2002; Дядечко/Djadechko, 2006; Шулежкова/Shulezhkova, 2013; Ломакина, Мокиенко/ Lomakina, Mokienko, 2019). Die Verbindung zwischen den geflügelten Worten und deren Textquellen bleibt in den Gedanken der Muttersprachler in assoziativer Form behalten, kann aber mit der Zeit verschwinden, und dann werden die geflügelten Worte zu phraseologischen Einheiten oder Sprichwörtern. Dazu führt auch das, dass viele geflügelte Worte als fertige Wortkomplexe in der Sprache weit verbreitet sein konnten, lange bevor sie zu einem Teil des Textes wurden, mit dem sie später ständig assoziiert wurden (Иванов/ Ivanov, 2003). Einige Sprachwissenschaftler definieren geflügelte Worte als eine Art von aphoristischen Einheiten (Ivanov, 2016; Іваноў/Ivanou, 2017a; Іваноў/Ivanou, 2017b: 40-41; Иванов/Ivanov, 2018).

Das moderne geschriebene Belarussisch, das eine moderne nationale und europäische Sprache ist, verwendet eine große Anzahl der geflügelten Worte, die aus Einheiten sowohl rein belarussischen Ursprungs (Янкоўскі/Yankouski, 1961; Іваноў, Іванова/Іvanou, Ivanova, 1997), als auch aus Entlehnungen aus anderen (auch deutschen) Sprachen (Венідзіктаў, Іваноў/Venidziktau, Ivanou, 2002; Венідзіктаў/Venidziktau, 2003; Крылатыя выразы/Krylatyja vyrazy, 2004; Крылатыя выразы/Krylatyja vyrazy, 2006; Цеплякова/Cepljakova, 2007; Цеплякова/Cepljakova, 2009a; Цеплякова/Cepljakova, 2009b; Цеплякова/Cepljakova, 2009в; Цеплякова/Cepljakova, 2010a; Цеплякова/ Cepljakova, 2010b; Іваноў/Ivanou, 2011; Теплякова/Tepljakova, 2011a; Теплякова/ Tepljakova, 2011b; Іваноў, 2014; Цеплякова/Cepljakova, 2015; Tepljakowa, 2019) bestehen. Literarische Werke verschiedener Genres, Aussprüche berühmter Personen (Лепешаў/Lepeshau, 1986; Лепешаў/Lepeshau, 1992; Мiхневіч/Mihnevich, 1994) sowie die Folklore (Іваноў/Ivanou, 2005) stellen die Hauptquellen für die aus anderen Sprachen entlehnten geflügelten Worte dar. 
Die Definition von Sprach- und Textquellen der geflügelten Einheiten in der belarussischen Sprache vor dem Hintergrund der europäischen Sprachen (Иванов/Ivanov, 2013а) ist ein aktuelles Problem des Studiums der belarussischen Paremiologie und Aphoristik im europäischen Kontext (Иванов/Ivanov, 2013b) und war als Forschungsschwerpunkt von Linguisten der Mogiljower Staatlichen Universität namens A. Kuleschow im Laufe der letzten Jahren (Иванов, Иванова/Ivanov, Ivanova, 2012; Іваноў/Ivanou, 2016а; Іваноў/ Ivanou, 2016b) herausgearbeitet. Die Identifizierung der Quellen von geflügelten Worten, insbesondere von solchen, die aus anderen Sprachen stammen, ist von unbestreitbarer Bedeutung für den kontinuierlichen Aufbau ihres Verständnisses und ihrer Wiedererkennung in der Sprache. Der Erwerb der geflügelten Worte einer anderen Sprache ist aber nicht nur aus Gründen der Wissenserweiterung und damit des besseren Verständnisses fremdsprachiger Texte wichtig. Die geflügelten Ausdrücke, besonders die nationalen Ursprungs, sind auch eine reiche Quelle linguolandeskundlicher Informationen über das entsprechende Land, dessen Geschichte und Kultur.

Für die belarussischen Studierenden, da in Belarus Deutsch als Fremdsprache studiert und gelernt wird, ist die Kenntnis der geflügelten Worte, die für die heutige Bevölkerung der deutschen Muttersprachler aktuell sind, beim Erlernen der deutschen Sprache von großer Bedeutung, insbesondere im Hinblick auf die Erleichterung der interkulturellen Kommunikation (Иванов/Ivanov, 2007; Иванов/Ivanov, 2008; Иванов/Ivanov, 2012). Nicht alle geflügelten Worte aus deutschen literarischen Quellen sind in den Wörterbüchern der belarussischen Sprache lexikalisiert (Іваноў, Цеплякова/Ivanou, Cepljakova, 2019). Seit der Veröffentlichung des Wörterbuchs „Geflügelte Worte“ von G. Büchmann ist viel Zeit vergangen und durch seinen Lauf sind viele Phrasen, Redewendungen und Ausdrücke, die vom Autor in seinem Buch lexikalisiert sind, die zum Zeitpunkt der Veröffentlichung relevant waren, inzwischen in Vergessenheit geraten und werden in der heutigen Zeit kaum noch verwendet, während viele andere ihren Platz eingenommen haben. Es besteht daher eine dringende Notwendigkeit einer lexikografischen Beschreibung jener, d.h. der heute in der deutschen Sprache verwendeten geflügelten Ausdrücke (vor allem in gedruckten Ausgaben, populären literarischen Werken, Reden von staatlichen, politischen, öffentlichen Personen und Kulturschaffenden).

Im angegebenen Artikel werden die Prinzipien der Erstellung und die Struktur des Wörterbuchs der modernen deutschen geflügelten Worte für Belarussen, die Deutsch als Fremdsprache studieren oder lernen, definiert werden.

\section{Die Textquellen der deutschen geflügelten Worte}

In der modernen deutschen Schriftsprache wird eine große Anzahl von festen Redewendungen angewendet, die aus verschiedenen Quellen - literarischen Werken, folkloristischen Texten, Texten der Massenkommunikation, Titeln von künstlerischen Werken, Aussprüchen berühmter Personen, anonymen literarischen Werken, Beinamen bekannter Personen und literarischer Helden - in der deutschen Sprache und in anderen europäischen Sprachen stammen. Für das Wörterbuch der geflügelten Worte, das für die Deutsch 
als Fremdsprache studierenden Belarussen bestimmt ist, sind die geflügelten Worte aus ursprünglich deutschen Textquellen am wichtigsten.

Geflügelte Worte deutschen Ursprungs stammen aus verschiedenen Textquellen, von denen die folgenden die wichtigsten sind:

- literarische Werke, z.B.: das Ding an sich - ein Ausdruck aus dem Werk „Kritik der reinen Vernunft“ (1781) des deutschen Philosophen Immanuel Kant (1724-1804); die blaue Blume - ein Ausdruck aus dem Roman „Heinrich von Ofterdingen“ (1802) des deutschen Schriftstellers Novalis (1772-1801); Es ist eine alte Geschichte - ein Ausdruck aus dem Gedicht „Ein Jüngling liebt ein Mädchen“ (1822) des deutschen Dichters Heinrich Heine (1797-1856);

- folkloristische Texte, z.B.: auf großem Fuß leben - ein Ausdruck, der auf eine historische Anekdote zurückgeht, die behauptet, dass die mittelalterliche Mode des Tragens von Schuhen mit langen, scharfen, nach oben gebogenen Schuhspitzen, deren Größe angeblich den Grad des Adels und des Reichtums ihres Besitzers symbolisierte und durch ein spezielles Gesetz bestimmt wurde, ihre Entstehung dem englischen König Heinrich II. Plantagenet (1133-1189) verdankt, der solche Schuhe trug, weil er eine Wucherung am rechten Daumen hatte;

- Texte der Massenkommunikation, z.B.: Faustrecht - die Darlegung eines der Gesetze der Talion, die in den 11.-13. Jh. in Deutschland verbreiteteste Form der Entscheidung der Gerichtsverhandlungen - mit Waffengewalt; Kanonen statt Butter eine militaristische Losung, ausgesprochen im Jahre 1936 vom deutschen Staatsmann Rudolf Richard Hess (1894-1987), einem der Oberhäupter des Hitlerreiches; Proletarier aller Länder, vereinigt Euch! - ein Aphorismus aus dem „Manifest der Kommunistischen Partei“ (1848) der deutschen Philosophen und politischen Figuren Karl Marx (1818-1883) und Friedrich Engels (1820-1895), wurde später zur Losung der internationalen Arbeitsbewegung: „Proletarier aller Länder vereinigt Euch!“‘;

- Titel von künstlerischen Werken, z.B.: Jenseits von Gut und Böse - der Titel eines Werkes (1886) des deutschen Philosophen Friedrich Nietzsche (1844-1900); Die Frau meiner Träume - der Titel eines Films (1944) des deutschen Regisseurs Georg Jacoby (1882-1964); Lieder ohne Worte - der Titel einer Sammlung von Musikstücken (1829-1845) des deutschen Komponisten Jakob Ludwig Felix Mendelssohn Bartholdy (1809-1847);

- Aussprüche berühmter Personen, z.B.: Ideendrama - ein Ausdruck des bekannten deutschen theoretischen Physikers und Wissenschaftlers Albert Einstein (1879-1955); Lebensraum - ein Ausdruck des deutschen Politikers und Bankiers Hjalmar Schacht (1877-1970), eines der Oberhäupter des Dritten Reiches, aus der Rede vom 7. Dezember 1930; Nervenkrieg - ein Ausdruck des deutschen Generalfeldmarschalls Paul von Hindenburg (1847-1934), des Reichspräsidenten der Weimarer Republik (19251934), der im Interview mit einem Reporter von der österreichischen Zeitung „Neue Freie Presse“ am 19. November 1914 sagte: „Der Krieg mit Russland ist gegenwärtig vor allem eine Nervenfrage. Wenn Deutschland und Österreich-Ungarn die stärkeren Nerven haben und durchhalten werden - und sie werden durchhalten! - so werden wir siegen!"“; 
- anonyme literarische Werke, z.B.: neue Ordnung - ein Ausdruck aus den deutschen Periodika in den 30er-Jahren des 20. Jh., der später für die Bezeichnung des NaziRegimes, eingeführt in Deutschland vom Führer der Nationalsozialistischen Partei Adolf Hitler (1889-1945), angewendet wurde;

- Beinamen bekannter Personen und literarischer Helden, z.B.: der eiserne Kanzler der Beiname des deutschen Politikers und Staatsmanns Otto von Bismarck (18151898), des ersten Reichkanzlers des Deutschen Reiches (1871-1890).

\section{Die Prinzipien des Aufbaus des Wörterbuches}

Im von uns erstellten Wörterbuch werden etwa 400 geflügelte Worte erarbeitet, die in der modernen deutschen Schriftsprache unter Berücksichtigung ihrer Varianten und Nebenformen verwendet werden. Jedes geflügelte Wort wird durch eine Erklärung seiner Bedeutung und ggf. der Situation seiner Verwendung, illustrative Zitate aus Zeitungs- und Zeitschriftenartikeln, populären künstlerischen und wissenschaftlichen Werken, Reden von Politikern und öffentlichen Personen ergänzt. Historisch-etymologische Informationen und Verweise auf das Wörterbuch „Geflügelte Worte“ von G. Büchmann (Ausgaben von 1972 und 2018) sind auch angegeben.

\section{Der Aufbau des Wörterbuchartikels}

\subsection{Das Stichwort}

Die geflügelten Worte als Stichwörter der Wörterbuchartikel werden in ihrer am häufigsten gebrauchten Form angeführt. Andere lexikalisch-grammatische Varianten in der Zusammensetzung der geflügelten Worte werden in runden Klammern nach jenem Wort oder jenen Wortkombinationen angegeben, die ersetzt werden. Jene lexikalischen Komponenten oder strukturellen Teile eines geflügelten Wortes, die in der Sprache reduziert werden, sind fakultativ, da sie keinen Beitrag zur eigentlichen Bedeutung leisten, und werden in gebrochenen Klammern angegeben, z.B.: < Baron> Münchhausen; Der Krieg ist $<$ nichts anderes als $>$ die Fortsetzung der Politik mit anderen Mitteln; Die Architektur ist erstarrte Musik (verstummte Tonkunst); Die natürliche Auslese (Auswahl, Selektion); Ein mephistophelisches Gelächter (Lächeln); Kinder, Küche, <Kleider >, Kirche; Morgen, morgen! nur nicht heute! <Sagen alle faulen Leute $>$ usw.

\subsection{Die Bedeutungserklärung, situative und expressiv- bewertende Charakteristiken der geflügelten Worte}

Die vorgegebene Erläuterung der geflügelten Worte im Wörterbuch ist zweifach: Es betrifft sowohl eine logische Charakteristik ihrer direkten oder bildlichen Bedeutung als auch eine situative und expressiv-bewertende Charakteristik.

Die einzelnen Erklärungen bestehen aus einer detaillierten Beschreibung jenes Begriffs oder jener Situation und einer entsprechenden Spracheinheit. Der Bedeutungserklärung 
der geflügelten Worte ist das Icon $\square$ vorangestellt, z.B.: Das Ewigweibliche $\square$ Über einen unvergänglichen, zeitlosen weiblichen Liebreiz. Den Wald vor lauter Bäumen nicht sehen $\square$ Die Hauptsache wegen vieler Details nicht sehen. Die fröhliche Wissenschaft $\square$ Die metaphorische Bezeichnung der Philosophie.

In Fällen, wobei das geflügelte Wort mehrere Bedeutungen hat, werden sie alle zusammen angegeben und entweder nummeriert oder durch ein Semikolon getrennt, z.B.: Ein mephistophelisches Gelächter (Lächeln) $\square$ 1. Ein böser, sarkastischer Spötter; Zyniker. 2. Ein sarkastisch böses Lachen; ein böses, sarkastisches Lächeln. Kategorischer Imperativ $\square$ Über die zwingende und unüberwindliche Notwendigkeit, etwas zu tun; über die Anforderung der Zeit, der Epoche sowie über die Lebenseinstellung des Einzelnen. Neue Ordnung $\square$ Faschistische Macht; jedes militärische, totalitäre Regime.

Die situative Charakteristik beinhaltet die Bereitstellung spezifischer Informationen über die Umstände, unter denen ein bestimmtes geflügeltes Wort verwendet werden könnte: wo, wann, in Bezug auf was oder wen, unter welchen Bedingungen, mit welchem Zweck usw. Die Beschreibung der typischen Situation des Gebrauchs eines Ausdrucks beginnt mit den Worten: „Es wird zitiert, wenn ... “, z.B.: Den Dolch im Gewande $\square$ Es wird zitiert, wenn es um Situationen geht, in denen es eine Intrige, Geheimhaltung, Spionage oder irgendwelches Geheimnis gibt. Der Mohr hat seine Schuldigkeit getan, der Mohr kann gehen $\square$ Es wird zitiert, um zynische Gleichgültigkeit einem Menschen gegenüber zu bezeichnen, dessen Dienste man nicht mehr braucht. Verweile doch! Du bist so schön! $\square$ Es wird zitiert, wenn man den höchsten Grad an Freude, Bewunderung für etwas zum Ausdruck bringt, sowie scherzhaft, wenn man jemanden oder etwas fotografieren, zeichnen oder verzögern usw. will.

Die expressiv-bewertende Charakteristik steht als zweiter Aspekt der Erklärung zum Gebrauch eines bestimmten geflügelten Wortes und soll das Vorhandensein von Nuancen der Zustimmung, der Verurteilung, des Scherzes oder der Ironie differenzieren, z.B.: Die blonde Bestie $\square$ 1. Eine ironische Charakterisierung einer starken Persönlichkeit, des Vertreters einer weißen Rasse, der sich seiner Überlegenheit gegenüber anderen Menschen sicher ist. 2. Im Allgemeinen über Blondinen. Ein Gespenst geht um in Europa - das Gespenst des Kommunismus $\square$ Man spricht (in letzter Zeit oft ironisch oder mit Verurteilung) über die Ausbreitung der Idee des Aufbaus einer kommunistischen Gesellschaft sowie über alles, was bald erscheinen könnte. Religion ist Opium für das Volk $\square$ Es wird oft missbilligend oder ironisch hinsichtlich des Gottes zitiert. Die geflügelten Worte, die in ihrer expressiv-bewertenden Charakteristik neutral sind, werden in keiner Weise bezeichnet.

\subsection{Das Bildmaterial}

Die Semantik des geflügelten Wortes, seine situative und expressiv-bewertende Charakteristik, die Verfahren zu seinem Gebrauch im Kontext werden im Wörterbuch durch Zitate aus Zeitungen und Zeitschriften, künstlerischen, wissenschaftlichen und wissenschaftlich-populären Werken, Reden von staatlichen, politischen, öffentlichen Personen und Kulturschaffenden illustriert. Das Bildmaterial wird in Übereinstimmung mit den in den Originalquellen verwendeten deutschen Rechtschreibregeln zur Verfügung gestellt. Jedes Zitat aus Zeitungen und Zeitschriften ist mit dem Namen der Zeitung oder Zeitschrift, dem 
Datum (der Ausgabe) und dem Jahr der Ausgabe, aus einem literarischen Werk - mit dem Namen des Autors und dem Titel des Werkes versehen. Dem Bildmaterial ist das Icon $\mathbb{E}$ vorangestellt, z.B.: Das Ding an sich $\mathbb{E} \mathbb{D}$ Der Irre und der Positivist sind nur Kehrseiten derselben Medaille. Der Schizo ist selbst das Ding an sich, das er zu sehen glaubt, wie es noch vor seinem Blick ist. Er ist das tote Ding an sich, das er nicht hat und nicht erkennt. Das verbindet ihn mit dem Logiker, dessen Gegner er angeblich ist. Mathematik und Schizophrenie haben dieselbe menschliche Wurzeln, wie oft notiert wurde. Der Schizo ist alles andere als der heute glorifizierte Widerstandskämpfer gegen eine naturbeherrschende Systemrationalität, sondern selber der rationale Machtwille, dessen Todfeind er sein soll. (R.F. Schütt, „Zurück zur postökologistischen Natur. Über metapolitische Methoden der Ganzheit und der Differenzen“). Der Kampf ums Recht 미 „Der Kampf ums Recht ist hart, aber er ist nötig“ [Titel des Artikels]. („Braunschweiger Zeitung“, 14.05.2009). Die bürgerliche Gesellschaft $\mathbb{E} D$ Ich zitiere: Um die bürgerliche Gesellschaft zu zerstören, muss man ihr Geldwesen verwüsten. (Protokoll der Sitzung des Parlaments Deutscher Bundestag am 29.03.2012. 172. Sitzung der 17. Wahlperiode 2009-. Plenarprotokoll). Sternstunde $\mathbb{C D}$ Der Satz ist wie gemünzt auf die elf Monate zwischen dem 9. November 1989 und dem 3. Oktober 1990, zwischen Mauerfall und Wiedervereinigung. Es war die Sternstunde der jüngsten deutschen Geschichte. (H. Köhler, Ansprache von Bundespräsident Horst Köhler anlässlich der Verleihung des Großen Verdienstkreuzes mit Stern des Verdienstordens der Bundesrepublik Deutschland an Bundesminister a.D. Peter Struck). Umwertung aller Werte $\mathbb{C} \mathbb{d}$... der gewaltigen Häresie bewusst. McDonald's hat damit die Umwertung aller Werte im System der Ernährung vollendet. Die Götter in Weiß... (W. Meisinger, ,Trüffel für alle“// „Falter“, 11.12.2019).

Illustrative Zitate, in denen geflügelte Worte in einer paraphrasierten (schriftstellerischen) Form verwendet werden, sind mit einem Sternchen * gekennzeichnet, z.B.: Blut und Eisen oder Eisen und Blut $\mathbb{E d}$ * ,Reichsbürger verteidigen ihr "Staatsgebiet mit Blut, Eisen und Feuer"“ [Titel des Artikels]. („Nordkurier“, 25.06.2018). Geist des Widerspruchs $\mathbb{C}$ * ,, Geist der Anarchie“ [Titel des Artikels]. (M. Papst // „NZZ am Sonntag“, 03.04.2016). Der Krieg ist < nichts anderes als $>$ die Fortsetzung der Politik mit anderen Mitteln $\mathbb{E} \mathbb{D}^{*}$ Ein solcher Krieg ist jedoch nicht mehr die Fortsetzung der Politik mit anderen Mitteln, sondern mit denselben Mitteln. Im großen Krieg kontrolliert die Politik eine an sich unpolitische Gewalt. Im kleinen Krieg, so die Gefahr, kontrolliert das Militär, wider Willen, eine an sich politische Gewalt. (Th. Rid, „Wenn Generäle Politik machen“// „Die Zeit“" (Online-Ausgabe), 17.04.2008, Nr. 16).

\subsection{Die historisch-etymologische Auskunft}

Die historisch-etymologische Auskunft besteht aus dem Titel und dem Veröffentlichungsdatum des Werkes, aus dem das geflügelte Wort stammt, und enthält außerdem den vollen Namen und die Lebensjahre des Autors. Der Autorenkontext der Verwendung des geflügelten Wortes wird nur in den Fällen erklärt, in denen seine Kenntnis zum Verstehen der Bedeutung einer entsprechenden Einheit notwendig ist. Der historisch-etymologischen Auskunft ist das Icon $\Leftarrow$ vorangestellt (das wiederholt werden kann, wenn das geflügelte Wort mehrere fremdsprachige Quellen hat), z.B.: Aufforderung zum Tanz $\Leftarrow$ „Aufforderung 
zum Tanz “ - der Titel eines Klavierstücks (1819) des deutschen Komponisten, Dirigenten und Pianisten Carl Maria von Weber(1786-1826). Der Mohr hat seine Schuldigkeit getan, der Mohr kann gehen $\Leftarrow$ ein Ausdruck aus dem Drama „Die Verschwörung des Fiesco zu Genua“" (1783) des deutschen Dichters und Dramatikers Friedrich Schiller (1759-1805). Es irrt der Mensch, solang er strebt $\Leftarrow$ ein Ausdruck aus der Tragödie „Faust“ (1808) des deutschen Schriftstellers und Naturforschers Johann Wolfgang Goethe (1749-1832).

Die historische Auskunft sollte die Gründe und Bedingungen des Gebrauchs des geflügelten Wortes von seinem Autor sowie die Besonderheiten des Funktionierens des geflügelten Wortes außerhalb des Textes erklären, z.B.: Blut und Eisen oder Eisen und Blut $\Leftarrow$ ein Ausdruck des damaligen preußischen Ministerpräsidenten Otto von Bismarck (1815-1898) aus der Rede vom 30. September 1862 vor der Budgetkommission des preußischen Abgeordnetenhauses: „Nicht durch Reden oder Majoritätsbeschlüsse werden die großen Fragen der Zeit entschieden, das war der große Fehler von 1848 und 1849, sondern durch Eisen und Blut.“ Das Sein bestimmt das Bewusstsein $\Leftarrow$ ein Ausdruck aus dem Vorwort zum Werk ,Zur Kritik der politischen Ökonomie“ (1859) des deutschen Philosophen und der politischen Figur Karl Marx (1818-1883), einer der fundamentalen Grundsätze der Philosophie des Materialismus: „Es ist nicht das Bewusstsein der Menschen, das ihr Sein, sondern umgekehrt ihr gesellschaftliches Sein, das ihr Bewusstsein bestimmt.“ Minderwertigkeitskomplex $\Leftarrow$ ein Ausdruck aus der Arbeit „Studie über Minderwertigkeit von Organen“ (1907) des österreichischen Arztes Alfred Adler (1870-1937), in der die Theorie der affektiven Reaktion des Individuums auf reale oder imaginäre körperliche oder geistige Defekte bewiesen wird.

Wenn das geflügelte Wort mehrere fremdsprachige Quellen hat, werden die Informationen über diese Quellen in chronologischer Reihenfolge angegeben, z.B.: Die geheimnisvolle Natur $\Leftarrow$ ein Ausdruck aus dem Roman „Problematische Naturen“ (1861) des deutschen Schriftstellers Friedrich Spielhagen (1829-1911). $\Leftarrow$ ein Ausdruck aus dem „Maximen und Reflexionen“ (1833) des deutschen Naturforschers und Schriftstellers Johann Wolfgang Goethe (1749-1832). Götterdämmerung $\Leftarrow$,, Götterdämmerung “- der Titel eines Werkes (1888) des deutschen Philosophen Friedrich Nitzsche (1844-1900). $\Leftarrow$,, Götterdämmerung “- der Titel einer Oper (1874) des deutschen Komponisten Richard Wagner (1813-1883). Weltschmerz $\Leftarrow$ ein Ausdruck aus der Schrift „,Aus der GemäldeAusstellung von 1831“ (1831) des deutschen Dichters Heinrich Heine (1797-1856): „Welchen großen Weltschmerz hat der Maler hier mit wenigen Strichen ausgesprochen“. $\Leftarrow$ ein Ausdruck aus dem Werk ,Selina, oder Über die Unsterblichkeit der Seele“ (1827) des deutschen Schriftstellers Jean Paul Friedrich Richter (1763-1825).

Die Herkunft der Prototypen von geflügelten Worten wird unmittelbar nach der etymologischen Auskunft gesondert erläutert, z.B.: Fliegender Holländer $\Leftarrow$,Fliegender Holländer “ - der Titel einer Oper (1841) des deutschen Komponisten Richard Wagner (1813-1883). $\Leftarrow$ ein Ausdruck aus einer mittelalterlichen niederländischen Legende (niedergeschrieben 1830), in der es um einen Seemann geht, der in einem heftigen Sturm schwor, das Kap herumzuumsegeln, das ihm im Weg lag, auch wenn es ewig dauern würde, aber wegen seines Stolzes war er dazu verdammt, für immer auf einem Schiff im stürmischen Meer zu segeln und niemals das Ufer zu erreichen. 


\subsection{Die lexikografische Auskunft}

Die lexikografische Auskunft zeigt, in welchen lexikografischen Quellen in der deutschen Sprache das Stichwort oder seine Varianten lexikalisiert werden.

Als Quelle wurde das Wörterbuch „Geflügelte Worte“ von G. Büchmann (Ausgaben von 1972 und 2018) gewählt. Es ist jedoch wichtig zu beachten, dass es keine vollständige Kongruenz in der Lexikalisierung von geflügelten Wörtern zwischen dem von uns erstellten Wörterbuch, das sich auf den modernen deutschen Sprachgebrauch konzentriert, und dem Wörterbuch von G. Büchmann.

\subsection{Entsprechungen und Äquivalente in der belarussischen Sprache}

Dieser Abschnitt des Wörterbuchartikels enthält Entsprechungen und Äquivalente des deutschen geflügelten Wortes in der modernen belarussischen Sprache. Für jede belarussische Entsprechung oder jedes belarussische Äquivalent wird gezeigt, in welchen lexikografischen Quellen die Einheit in der belarussischen Sprache ursprünglich lexikalisiert wurde. Dem belarussischen Material ist das Icon $\approx$ vorangestellt, z.B.: Geistes Aristokratismus $\approx$ Belarussisch: арыстакрат духу. Наmmer und $\mathbf{A m b o \beta} \approx$ Belarussisch: паміж молатам і кавадлам. Kommentar überflüssig $\approx$ Belarussisch: каментарыі лішнія (непатрэбныя). Verweile doch! Du bist so schön! $\approx$ Belarussisch: Спыніся імгненне! <Ты цудоўнае!>.

\section{Die Muster der Wörterbuchartikel}

\section{Absoluter Geist}

$\square$ Eine absolute Idee, die den Prozess ihrer Selbsterkenntnis beendet und zu ,absolutem Wissen" führt.

$\mathbb{E}$ Dichts vereinigt Philosophen heute inniger als das Lob der Differenz. Postmodernes Denken ist vor allem die strikte Weigerung, die Vielfalt der Einzelerscheinungen auf ein gründendes Prinzip zurückzuführen. Dass kein ,, absoluter Geist“ die Welt im Innersten zusammenhält, ist, wie zahlreiche Studien seit Jahrzehnten zu beweisen versuchen, eine Einsicht, die um 1800 bereits verbreitet war - auch und gerade bei jenen Philosophen und Dichtern, die noch vom „Unbedingten“, „Höchsten“, „Göttlichen“ handelten. („Des Widerspenstigen Fügung“"/ „Neue Zürcher Zeitung“, 13.05.2009).

Der von Gott zu den Menschen geschickte Jesus zeige, „dass Gott nicht einfach ein unerreichbarer, aus der Ferne anzuvisierender absoluter Geist ist, sondern, dass er uns begleitet“, sagte Lehmann. Der Sohn Gottes bringe uns „Leben aus Gott“, und „genau da müssen wir den Geist ansiedeln“, betonte der Kardinal. Was Gott tue, sei, dass er uns ,,immer wieder lebendig macht" und uns „Beistand“ gebe. („Gott ist kein unerreichbarer Geist" // „Allgemeine Zeitung“, 02.06.2009).

Gabriel: Tatsächlich könnte man provozierend sagen, dass der Sinn der Religion die Einsicht ist, dass es Gott nicht gibt, dass Gott kein absoluter Geist ist, der den Sinn unseres Lebens garantiert. Deswegen ist aber die Religion selbst oder die Rede von Gott nicht sinnlos. Ohne Religion wäre es niemals zu Metaphysik, ohne die Metaphysik niemals zu 
Wissenschaft und ohne die Wissenschaft niemals zu den Erkenntnissen gekommen, über die wir heute verfügen. („Eine Reise durch das Unendliche“// „Der Spiegel“, 01.07.2013).

$\Leftarrow$ Der Begriff der Philosophie des deutschen Philosophen Georg Wilhelm Friedrich Hegel (1770-1831).

$\approx$ Belarussisch: абсалютны дух.

\section{Der eiserne Kanzler}

$\square$ 1. Der Spitzname von Otto von Bismarck. 2. Über einen Mann mit einem festen, unbeugsamen Willen.

[D] Wolfgang Schüssel Der eiserne Kanzler ist kultureller Generaldilettant. Er spielt entfesselt Boogie-Woogie, furchtfrei Fußball und seine Cartoons gehören zum Lustigsten, was die ÖVP neben Andreas Khols Aphoristik hervorbringt. Jemand mit diesem Kaleidoskop an „Talenten“" muss sich in der Gewissheit wähnen, auch auf anderen Gebieten genial zu sein. Für Freund wie Feind ist es nun unerheblich, ob Schüssel auch politisches Talent hat. Allein mit der Fama von seiner Brillanz bringt er all die wunderlichen Reformen und Gesetze durch, die das Leben in Österreich zunehmend zur Qual machen. („Böse wie nie!““// „Falter“, 22.12.2004).

Grell wird hinter die Fassade der Rot-Grünen geleuchtet werden, wo nicht der eiserne Kanzler des Jahres 2004 regiert, sondern die Ratlosigkeit. Nach kaum zwei Monaten müssen sich Gerhard Schröder und SPD-Chef Franz Müntefering von ihrer Planung für das Jahr verabschieden. Sie hatte sich für 2005 nichts Neues vorgenommen - aber die Rechnung ohne den Wähler gemacht, der darauf wartet, dass seine Regierung regiert. (N. Blome, „Hinter der Fassade“"/ „Berliner Morgenpost“, 25.02.2005).

Erst gegen Ende von Schmidts aktiver politischer Laufbahn sickerte ab 1984 langsam durch, dass sein Vater, das uneheliche Kind, großväterlicherseits selbst jüdischer Abstammung war. Dass die Schmidts dies nach 1933 geheim hielten und verbargen, ist nur zu verständlich. Dass er sich aber in der Bundesrepublik so lange über diese Geschichte ausschwieg und auch darauf beharrte, die Gräuel des Holocausts erst nachträglich erfahren zu haben, hielt ihm sogar seine Tochter später vor. Der Geschichte mit dem jüdischen Vorfahren verlieh Schmidt mit steigendem Alter größere Autorität. Doch warum hatte sich der ,eiserne Kanzler “ nicht schon früher dazu bekannt? (A. Fanizadeh, „Gespaltenes Bewusstsein - der verstorbene Altkanzler war ein wichtiger Gestalter der demokratischen Bundesrepublik. In seiner Verstocktheit aber auch ein typischer Repräsentant der Wehrmachts- und Kriegsgeneration“// „Die Tageszeitung“, 14.11.2015).

„Der eiserne Kanzler“ [Titel des Artikels]. („Braunschweiger Zeitung“, 30.08.2008). „Euro macht Merkel zur eisernen Kanzlerin“ [Titel des Artikels]. („Die Südostschweiz“, 01.01.2012).

$\Leftarrow$ Der Beiname des deutschen Politikers und Staatsmanns Otto von Bismarck (18151898), des ersten Reichkanzlers des Deutschen Reiches (1871-1890).

$\approx$ Belarussisch: жалезны канцлер.

\section{Die Frau meiner Träume}

$\square$ Über das Mädchen, das man erwünscht.

[Dd Perry-Schuhe sind eine Hommage an die Weiblichkeit. Alles an ihnen ist verführerisch: weiches Leder, in zarte Farben getaucht, edle Formen, durch elegante Absät- 
ze vollendet, zarte Seidenbänder sowie romantische Tüllschleifen mit verspielten Blütenund Federapplikationen. „Ich entwerfe Schuhe für die Frau meiner Träume“, sagt Michel Perry mit warmer, leicht rauher Stimme. „Sie verkörpert alle weiblichen Attribute. Auch wenn sie in dieser Vollkommenheit nur in meiner Fantasie existiert, so findet doch jede Frau in ihr ein Stück von sich wieder.“(„Michel Perry“// „Sonntagsblick“, 10.07.2005).

Eigentlich ist es nicht geschickt, dass ein Zuckerkranker neben einem Fliessband mit Pralinés steht. Andererseits haben Chips und Brot mehr Kohlenhydrate als Schokolade. Ich beschliesse, heute kein Brot mehr zu essen. Hinter dem Fliessband entdecke ich meine Traumfrau. 41 Jahre musste ich warten, bis ich sie gefunden habe. Die Frau meiner Träume trägt ein rotes Kleid und transparente Handschuhe. Zärtlich füllt sie die Teller auf, die an ihr vorbeifliessen. (B. Frenkel, „Im Zuckerhoch“ // „Tages-Anzeiger“, 15.03.2018).

Annamirl Bierbichler ist das Zentrum der frühen Filme, in der Olympiasiegerin ist sie ganz glamourös, die ideale Frau, wie direkt aus Hollywood. Und das alte Trauma wird sichtbar, das einst die Psychoanalyse aufdeckte und das Kino unaufhörlich umkreist: Die Frau meiner Träume, die mich geboren hat. Nie wird meine Mutter meine Frau! (F. Göttler, „Eine Beleidigung des bayerischen Volkes“// „Süddeutsche Zeitung“, 23.11.2018).

*Was ist für einen britischen Feuerwehrmann das Schönste? Neben seiner Braut? Nein - kein Grossbrand. Es ist ein grosser Cheeseburger. Einen 19 Kilo schwerer FleischKäse-Klops liessen sich jetzt Brandschutzexperte Tom Watts und Krankenschwester Kerry Schamp, beide 36, servieren. Als Hochzeitskuchen, von ihrem Lieblings-Restaurant, dem Zaks in Poringland in der englischen Grafschaft Norfolk. Ehemann Tom begeistert: „An einem Tag die Frau meiner Träume und den Burger meiner Träume - wunderbar!“ (,Sonntagsblick“, 05.10.2008).

$\Leftarrow$ „, Die Frau meiner Träume“- der Titel eines Films (1944) des deutschen Regisseurs Georg Jacoby (1882-1964).

z Belarussisch: дзяўчына маёй мары.

\section{Faustrecht}

\section{$\square$ Das Recht auf rohe Gewalt, das Recht der Starken.}

ㅁ] In Lorsch verteidigte der Bundesjustizminister das Gesetz als Garantie der Meinungsfreiheit: Mit kriminellen Hass-Posts und gezielten Falschnachrichten sollen Andersdenkende zum Schweigen gebracht werden, sagte er. Maas sprach sich klar gegen ein digitales Faustrecht im Netz aus. Ohne Druck aus der Politik würden die OnlineUnternehmen ihre Verpflichtungen allerdings nicht erfüllen. Die Vergangenheit habe dies eindeutig bewiesen. Strafbare Inhalte müssen schon länger aus dem Netz genommen werden. Das Gesetz soll nun eine härtere Gangart einleiten. („Hetze im Netz: Mehr Druck auf Facebook und Co. ausüben“// „Mannheimer Morgen“, 16.08.2017).

Das heisst: Die Nationalbank kann uns Sparer nicht mehr schützen. Wir müssen es selbst tun. Faustrecht auf dem Finanzmarkt. (Ph. Loser, Chr. Lenz, „Wir werden spekulieren müssen“"/ „Tages-Anzeiger“, 28.08.2019).

Gut also, ich plädiere in diesem Fall für „Mehr Freiheit und weniger Staat“, aber meine politischen Gegner in der Schweiz sollten nicht zu früh frohlocken. Die Unfreiheit, die in 
den USA geschaffen wird, kommt aus einem privaten Sicherheitsbedürfnis, das letztlich nur mit Reichtum zu befriedigen ist. Krankheit und Unfall können hier in die totale Armut führen, Sozialversicherungen sind selten und schlecht. So bleibt die Schadenersatzklage die einzige ,ausreichende“ Versicherung, und Haftpflicht wird zum Faustrecht. Auch schweizerische Verhältnisse und Wünsche erscheinen mir ab und zu als „typisch amerikanisch“, nämlich dann, wenn der Slogan „Mehr Freiheit und weniger Staat“ als Angriff auf unsere Sozialversicherungen gemeint ist. (P. Bichsel, „Im Gegenteil. Kolumnen 1986-1990“).

Demonstrationsrecht ja, Widerstandsrecht nein. Das muss klar sein. Dazu brauchen wir Konsens in diesem Haus, nicht nur wegen des 30. September, sondern auch im Blick auf das, was in Zukunft noch vor uns steht: ein 7-Milliarden-Euro-Projekt und viele andere Maßnahmen in diesem Land. In diesem Land geht nichts mehr, wenn das Faustrecht herrscht. (Protokoll der Sitzung des Parlaments Landtag von Baden-Württemberg am 02.02.2011. 108. Sitzung der 14. Wahlperiode 2006-2011. Plenarprotokoll).

„Trump führt Faustrecht im Welthandel ein“ [Titel des Artikels]. (Walter Niederberger // „Tages-Anzeiger“, 11.12.2019).

$\Leftarrow$ Die Darlegung eines der Gesetze der Talion, die in den 11.-13. Jh. in Deutschland verbreiteteste Form der Entscheidung der Gerichtsverhandlungen - mit Waffengewalt.

z Belarussisch: кулачнае права.

\section{Kanonen statt Butter}

$\square$ Ein Symbol für die Politik eines Staates, der sich auf Aggression vorbereitet und das Wohlergehen seines Volkes vernachlässigt.

[Dd Wollen wir die Gelegenheit beim Schopf packen, mit Moskau hart und wirksam über ausgewogene Abrüstung zu verhandeln und damit der Sowjetunion zu gestatten, ihre Mittel friedlichen Zwecken umzuwidmen? Oder wollen wir, dass die Russen bis ins 21. Jahrhundert hinein Kanonen statt Butter essen, während ihre Führer auf auswärtige Abenteuer sinnen, die sie von der heimischen Misere ablenken können: mehr Afghanistans, mehr Angolas, mehr Kubas? Wollen wir, dass unsere Enkel ihre eigenen Vietnams ausfechten müssen? (J. le Carre, „Warum ich aus der Kälte kam“ // „Die Zeit“ (Online-Ausgabe), 10.03.2011, Nr. 10).

Tim Schanetzky lehrt als Privatdozent Neuere und Neueste Geschichte in Jena. Zuletzt erschien von ihm Kanonen statt Butter. Wirtschaft und Konsum im Dritten Reich (C.H. Beck, München). (T. Schanetzky, „Die Stifter und die Lenker“ // „Süddeutsche Zeitung“" 20.08.2018).

„Kanonen statt Butter. Wirtschaft und Konsum im Dritten Reich“ (T. Schanetzky, „Walspeck gegen die Fettlücke“// „Zeit Geschichte“, 19.03.2019).

Wer den strategischen Ansatz „Kanonen statt Butter “ im Hinterkopf hat und der Verlängerung des Bundeswehrmandats in Afghanistan zustimmt, der spielt nicht nur mit dem Leben unserer Soldaten, der leitet auch einen Paradigmenwechsel in der deutschen Außenpolitik ein. (Protokoll der Sitzung des Parlaments Deutscher Bundestag am 12.11.2004. 139. Sitzung der 15. Wahlperiode 2002-2005. Plenarprotokoll).

„, Kanonen statt Butter “ [Titel des Artikels]. („Die Tageszeitung“, 09.02.2008, Nr. 8501, Jg. 29). 
$\Leftarrow$ Eine militaristische Losung, ausgesprochen im Jahre 1936 vom deutschen Staatsmann Rudolf Richard Hess (1894-1987), einem der Oberhäupter des Hitlerreiches.

z Belarussisch: гарматы замест масла.

\section{Kinder, Küche, $<$ Kleider $>$, Kirche}

$\square$ Die Liste der einzigen würdigen Beschäftigungen für eine Frau. Es wird meist scherzhaft-ironisch zitiert, um an die soziale Rolle der Frau und ihre Bestimmung zu erinnern.

$\mathbb{1}$ Nach dem Krieg trennte sich Deutschlands Frauenarbeitswelt: Im Westen galt die Vorgabe: Kinder, Küche, Kirche das Ideal der fleißigen Hausfrau. Im Osten durften und mussten die meisten arbeiten. Der Anteil erwerbstätiger Frauen stieg in der DDR Jahr für Jahr, bis er 1989 91,3 Prozent erreichte. Westdeutschland kam auf 51 Prozent. (K. Werner, „Weibliche Arbeitswelten. Gearbeitet haben Frauen natürlich schon immer. Sichtbar waren sie dabei aber lange nicht. Und unbezahlt noch dazu. Eine Chronologie von Kathrin Werner“// „Süddeutsche Zeitung“, 30.04.2019).

*Musik, Kinder, Küche, Klavier (E. Hartmann-Wolff, „Bestseller“// „FOCUS“, 15.10.2016).

*Viele Gedanken haben sich die Künstlerinnen über das Ausstellungsthema gemacht und sich auf KKK geeinigt. Dabei stehen die drei K nicht, wie es früher in den Köpfen unserer Urgroßväter verankert war, für Kinder, Küche, Kirche. Dabei lehnen Frauen heute weder die Freude am Kochen und Backen ab, noch sind sie antichristlich eingestellt, und Kinder erziehen sie nicht mit weniger Liebe und Freude als früher die Urgroßmütter. Doch das Leben der Frauen heute und ihr Lebenssinn ist umfangreicher als die bekannten drei K-Wörter. Kunst, Kult, Kritik sind die drei K-Wörter der Treidler-Frauen, die den Leitfaden der Ausstellung bilden. Die 13 Künstlerinnen haben viele Gedanken und Sichtweisen in ihren Bildern und Skulpturen eingebunden. Ist es Kunst? Ist es Kult? Ist es Kritik? Die Besucher dürfen gespannt sein: Wirkt die Wachstube anders als bei einer gemischten Ausstellung von Männern und Frauen? (,Treidler-Frauen sind dem Kampf der Geschlechter auf der Spur“ // „Rhein-Zeitung“, 11.05.2017).

*In sämtlichen Medien stoße man auf erniedrigende Stellungnahmen von Politikern, Geistlichen oder Journalisten an Frauen; in Talkshows des staatlichen Fernsehens würden Frauen öffentlich herabgesetzt und lächerlich gemacht. Die soziale Rolle der Frau, die kultiviert wird, ist die der Hüterin des Familienherds und der glücklichen Mätresse. Frauen sollten sich nur an die Glücksformel der fünf Ks halten: Kinder, Küche, Kirche, Kleider, Kaiser. Und kommt es dann zu Gewalttaten gegen Frauen, wird die Schuld nur zu gern dem Opfer gegeben und die anklagende Frau als Nestbeschmutzerin verunglimpft. (,Wo Frauen darum kämpfen, nicht zu Tode geprügelt zu werden“// „Die Presse“, 16.12.2019).

*Das Thema ist zumindest erkannt und wird entsprechend diskutiert. Die herkömmlich drei K’s, die für „Kinder, Küche, Kirche“ stehen, werden in den gender studies bereits geschlechtsspezifisch umgedeutet mit „Karriere, Konkurrenz, Kollaps “. (Protokoll der Sitzung des Parlaments Landtag Niedersachsen am 09.03.2005. 57. Sitzung der 15. Wahlperiode 2003-2008. Plenarprotokol).

$\Leftarrow$ Die berüchtigte Formel Wilhelms II. (1859-1941), des letzten deutschen Kaisers und preußischen Königs (1888-1918), zur Bestimmung des Schicksals einer Frau.

$\approx$ Belarussisch: дзеці, кухня, <адзенне>, царква. 


\section{Minderwertigkeitskomplex}

$\square$ Ein hypertrophiertes negatives Selbstwertgefühl, das zu Schüchternheit und Unsicherheit führt.

[D] Ja, Österreich ist das Land, in dem Grössenwahn und Minderwertigkeitskomplex zugleich auftreten. Wir sind die Tollsten, und wir sind das Letzte: beides zugleich. (E. Martin, „Ich war überrascht über die Blödheit“// „Tages-Anzeiger“, 12.07.2019).

Die Selbstbefreiung des Künstlers gelingt nur im Gelingen seiner Werke, nicht in der gelingenden Befreiung von der Kunst. Seit 20 Jahren versuche ich, meine ureigensten Antriebe und Regungen wenigstens auf dem geduldigen Papier in eine für mich und andere verständliche wie sinnlich reizende Form zu bringen, aber ich brauche keinen Minderwertigkeitskomplex, um meinen verzweifelten Versuchen einen großen Wert abzusprechen, sagt der zur Besinnung kommende Schriftsteller. (R.F. Schütt, „Am schnellsten vermehrt sich die Unfruchtbarkeit. Essays zur Multi-Kulturlosigkeit“").

Und dann saß Claudi an einem Tisch, inmitten von fremden Leuten, die überdreht und eingebildet waren. Udo tat ihr leid, er hatte jetzt ja immer mit solchen Städtern zu tun. Oder war es nur ihr Minderwertigkeitskomplex? Claudi schloss nicht aus, dass sie einen hatte. (U.M. Heim, „Das Rattenprinzip“).

Schauen Sie sich die Personal-Service-Agenturen an: Hier versuchen wir, die Defizite im Bereich der Dienstleistungen, die wir in Deutschland noch haben, zu überwinden. Ein Imageproblem besteht beispielsweise darin, dass die Zeit- und Leiharbeit mit einem gewissen Minderwertigkeitskomplex versehen ist. Wir müssen der Leiharbeit durch vernünftige und vor allem annehmbare Bedingungen der Entlohnung und Arbeitszeit zur Akzeptanz in der Gesellschaft verhelfen. (W. Schulz, „Hartz-Kommission“, Rede im Deutschen Bundestag am 07.11.2002).

„Nur was der Geist geschaffen hat, versteht er" - in diesem kurzen Satz verdichtet Dilthey seine Sicht auf Gegenstand, Methode und Besonderheit der Geisteswissenschaften. Und ein wenig klingt hier wohl auch jene Überlegenheit in der Erkenntnissuche an, die manche Geisteswissenschaftler lange Jahre für sich in Anspruch nahmen. Heute indes hat man manchmal den Eindruck, als sei das einstmals ausgeprägte Selbstbewusstsein der Geisteswissenschaften einem ausgewachsenen Minderwertigkeitskomplex, jedenfalls aber dem Gefühl einer deutlichen Vernachlässigung und Benachteiligung gegenüber den Naturwissenschaften gewichen. (H. Köhler, Grußwort von Bundespräsident Horst Köhler bei der Veranstaltung der Stiftung „Erinnerung, Verantwortung und Zukunft“ anlässlich des Abschlusses der Auszahlungen an die ehemaligen Zwangsarbeiter).

$\Leftarrow$ Ein Ausdruck aus der Arbeit ,Studie über Minderwertigkeit von Organen“(1907) des österreichischen Arztes Alfred Adler (1870-1937), in der die Theorie der affektiven Reaktion des Individuums auf reale oder imaginäre körperliche oder geistige Defekte bewiesen wird.

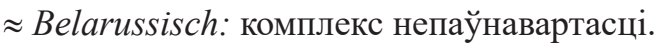

\section{Walpurgisnacht}

\section{$\square$ Über eine wilde, lärmende Versammlung.}

$\mathbb{E}$ Alt, hässlich, böse: So stellen sich kleine Buben eine Hexe vor. Es wird uns gleich ein wenig flau im Magen, wenn wir sehen, wie Thomas und Vroni im Film am Fenster ihrer 
kleinen Schlafkammer stehen und bange in Richtung Blocksberg schauen. Schon dämmert es. Die schlimmen Weibsbilder machen sich sicher gerade parat für den Hexentanz: Heia, Walpurgisnacht! Und wirklich, wenig später treffen sich da oben wahre Prachtexemplare der Kategorien alt, hässlich, böse. (B. Kugler, „Abraxas macht gut Wetter“ // „St. Galler Tagblatt"،, 14.02.2018).

Wenn Hexen und der Teufel sich treffen, um gemeinsam zum Brocken zu fliegen, ist in der Harzer Sagenwelt Walpurgisnacht. („Der Harz wird zum Hexenkessel“ // „Hannoversche Allgemeine“, 29.04.2019).

„Guten Morgen liebe Hexen und Zauberer! Hoffentlich haben alle Nachtschwärmer die Walpurgisnacht gut überstanden - denn jetzt beginnt er wieder, der Ernst des Lebens...“ (T. Kammerer, „Brandnotizen“).

Ich möchte mich da auf den Beschluss 5/902 aus dieser Periode beziehen, der charmanterweise zur Walpurgisnacht gefasst worden ist. Das war, glaube ich, der erste gemeinsame Beschluss, den SPD und CDU hier eingebracht haben und der auch eine Mehrheit bekommen hat. Wahrscheinlich war das Datum nicht ganz falsch gewählt, Hexerei musste damit im Spiel sein - das vermute ich mal ganz stark. (Protokoll der Sitzung des Parlaments Thüringer Landtag am 08.09.2010. 29. Sitzung der 5. Wahlperiode 2009-. Plenarprotokol).

„Walpurgisnacht im Mauerpark abgesagt“ [Titel des Artikels]. (S. Strauß // „Berliner Zeitung“, 15.04.2019).

„Zehntausende feiern die Walpurgisnacht“ [Titel des Artikels]. („Hannoversche Allgemeine", 02.05.2019).

$\Leftarrow$ Ein Ausdruck aus der Tragödie „Faust“ (1808) des deutschen Schriftstellers und Naturforschers Johann Wolfgang Goethe (1749-1832).

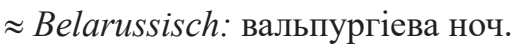

\section{Schlußfolgerung}

Das Wörterbuch richtet sich an die Wissenschaftler auf dem Gebiet der Phraseologie der germanischen Sprachen, Studenten und Hochschullehrer, Schüler und Lehrer der allgemein bildenden Schulen, Redakteure, Übersetzer und Dolmetscher sowie alle, die Deutsch als Fremdsprache studieren oder lernen, kann aber auch für deutsche Muttersprachler als normatives linguistisches Nachschlagewerk nützlich sein.

Das Wörterbuch kann im Bildungsprozess beim Unterricht von Deutsch als Fremdsprache an Hochschulen und allgemein bildenden Schulen sowie als Behelf beim Erlernen der Lexik und Phraseologie der modernen deutschen Schriftsprache und bei der Vorbereitung von Kurs- und Diplomarbeiten in der deutschen Sprache (verschieden Themen im Zusammenhang mit der deutschen Sprache, wie u.a. ihre Geschichte, Phraseologie und Paremiologie, oder Stilistik) effektiv eingesetzt werden.

Es kann auch als lexikografische Grundlage zur Erstellung eines deutsch-belarussischen (oder umgekehrt) Wörterbuches der geflügelten Worte benutzt werden. 


\section{Literatur}

Венідзіктаў С.В. (2003), Іншамоўныл крылатыя выразы у сучаснай беларускай мове, "Studia sławistyczne", 4, s. 121-130.

Венідзіктаў С.В., Іваноў Я.Я. (2002), Рускамоўныя запазычанні крылатых слоў у сучаснай беларускай мове, "Dziedzictwo przeszłości związków językowych, literackich i kulturowych polsko-bałto-wschodniosłowiańskich”, Białystok, VIII, s. 210-217.

Венідзіктаў С.В., Даніленка І.Л., Іванова С.Ф., Іваноў Я.Я. (2004), Крылатыл выразы y беларускай мове. Частка 1. 3 іншамоўных (еўрапейскіх і амерыканскіх) крыніи XIIХХ стст.: тлумачальны слоуннік, Магілёў.

Венідзіктаў С.В., Даніленка І.Л., Іванова С.Ф., Іваноў Я.Я., Чэх В.В. (2006), Крылатыя выразы ў беларускаймове. Частка 2. З рускамоўных літаратурных і фальклорных крыніи ХII-XX стст.: тлумачальны слоўнік, Магілёў.

Дядечко Л.П. (2002), Крылатые слова как объект лингвистического описания: история и современность, Киев.

Дядечко Л.П. (2006), “Крылатьй слова звук”, или Русская эптология, Киев.

Иванов Е.Е. (2003), О реккурентных прототипах крылатых фраз, “Славянская фразеология в ареальном, историческом и этнокультурном аспектах”, Гомель, с. 74-78.

Иванов Е.Е. (2007), Основные понятия качества лингвистического образования, "Восточнославянские языки в европейском языковом контексте”, Могилев, с. 8-12.

Иванов Е.Е. (2008), Качество лингвистического образования в Республике Беларусь (в аспекте межкультурной коммуникации), "Проблемы качества образования в Белоруссии и России в контексте интеграционных процессов”, Москва, 1, с. 161-170.

Иванов Е.Е. (2012), Общность задач преподавания русского и иностранных языков белорусам (в аспекте межкультурной коммуникации), "Восточнославянские языки и литературы в европейском контексте”, Могилев, с. 3-7.

Иванов Е.Е. (2013а), Белорусская паремиология и афористика в общеевропейском контексте (актуальные проблемы изучения), “XV Міжнародны з'езд славістаў = XV Международный съезд славистов = XV International Congress of Slavists”, Мінск, 1, с. 322-333.

Иванов Е.Е. (2013б), Белорусская паремиология и афористика в общеевропейском контексте (актуальные проблемы изучения), "Nationales und Internationales in der slawischen Praseologie", Greifswald, ss. 111-116.

Иванов Е.Е. (2018), Проблема объема и дифференциации класса высших (афористических) единиц языка (на материале русского и белорусского языков), “Восточнославянские языки и литературы в европейском контексте - V”, Могилев, с. 28-32.

Иванов Е.Е. (2000), Языковая природа крылатых слов, “Праблемы беларускага літаратуразнаўства", Мінск, с. 303-312.

Иванов Е.Е., Иванова С.Ф. (2012), Восточнославянская идиоматика в европейском языковом контексте, “Итоги научных исследований ученых МГУ им. А.А. Кулешова”, Могилев, с. 208-212.

Іваноў Я.Я. (2005), Крылатыя словы, “Беларускі фальклор: энцыклапедыя”, Мінск, 1, c. $729-730$. 
Іваноў Я.Я. (2011), Крылатыя афарызмы ў беларускай мове: з іншамоўных літаратурных і фальклорных крыніи VIII ст. да н. э. - ХХ ст.: тлумачальны слоўнік, Магілёў.

Іваноў Я.Я. (2014), Беларускія прыказкі з біблійных крыніи (матэрыялы да рускабеларуска-англійскага слоўніка біблеізмаў), “Авраамиевские чтения”, Смоленск, c. $11-24$.

Іваноў Я.Я. (2016а), Універсальнае і наџьяянальнае ў фразеалагічнай і парэміялагічнай падсістэмах беларускай мовы у еуррапейскім моўным кантэксие (актуальнасиь, метадалогія, перспектывы даследавання), “Славянская фразеология в синхронии и диахронии", 3, с. 46-49.

Іваноў Я.Я. (2016б), Фразеалогія, парэміялогія, афарыстыка беларускай мовы і іх сувязі з іншымі мовамі як напрамак даследаванняў навуковай школь па беларускаму і агульнаму мовазнаўству у МДУ імя А.А. Куляшова (1995-2015), “Итоги научных исследований ученых МГУ им. А.А. Кулешова 2015 г.”, Могилев, с. 91-93.

Іваноў Я.Я. (2017а), Афарыстычнае выказванне як моўная мадэль крылатых слоў, “Філологічні студіi”, 16, с. 114-121.

Іваноў Я.Я. (2017б), Афарыстычныля адзінкі у беларускай мове, Магілёў.

Іваноў, Я.Я., Іванова, С.Ф. (1997), Слоўнік беларускіх прыказак, прымавак $і$ крылатых выразаў: лінгвакраіназнаўчы дапаможнік, Мінск.

Іваноў Я.Я., Цеплякова А.Д. (2019), Літаратурныя крыніцы фразеалагічных адзінак, запазычаных з нямецикай мовы у беларускую мову (па-за межсамі этымалагічнага слоўніка фразеалагізмаў, "Немецкий язык лингводидактическое обеспечение и методика преподавания”, Могилев, с. 82-87.

Лепешаў І.Я. (1986), Крылатыя словы, “Энцыклапедыя літаратуры і мастацтва Беларусі", Мінск, 3, с. 137.

Лепешаў І.Я. (1992), Крылатыя словы і фразеалагізмы, “Роднае слова”, 9, с. 38-41.

Ломакина О.В., Мокиенко В.М. (2019), Крылатика в современном культурном контексте, “Вестник Российского университета дружбы народов”, Серия: Теория языка. Семиотика. Семантика, 10, 2, с. 256-272.

Міхневіч А.Я. (1994), Крылатыя словы, “Беларуская мова: энцыклапедыя”, Мінск, c. $273-274$.

Теплякова А.Д. (2011a), Иноязычные заимствования крылатых слов в белорусском и немецком языках, “Язык, культура, общество”, Москва, с. 125-126.

Теплякова А.Д. (2011б), Источники крылатых выражений в белорусском языке, “Фразеология и языковая динамика", Greifswald, Санкт-Петербург, с. 67-69.

Цеплякова А.Д. (2007), Структура, семантыка і функиылі запазычаных крылатых слоў y беларускай мове, “Славянская фразеология в ареальном, историческом и этнокультурном аспектах”, Гомель, с. 236-240.

Цеплякова А.Д. (2009а), Англамоўныя запазычанні крылатых слоў у сучаснай беларускай літаратурнай мове (колькасны склад $і$ крыніцы паходжання), “Веснік Мазырскага дзяржаўнага педагагічнага ўніверсітэта імя І.П. Шамякіна”, 2 (23), с. 162-166.

Цеплякова А.Д. (2009б), Нямецкамоўныя запазычанні крылатых слоў у сучаснай беларускай літаратурнай мове (колькасны склад і крыніџы паходжання), “Веснік Магілёўскага дзяржаўнага ўніверсітэта імя А.А. Куляшова”, 1 (32), с. 137-143. 
Цеплякова А.Д. (2009в), Франкамоўныя запазычанні крылатых слоў у сучаснай беларускай літаратурнай мове (колькасны склад і крыніџы паходжання), “Веснік Брэсцкага дзяржаўнага ўніверсітэта імя А.С. Пушкіна”, серыя філалагічных навук, 2 (12), c. $109-116$.

Цеплякова А.Д. (2015), Іншамоўныя запазычанні крылатых слоў у сучаснай беларускай мове, "Теоретические и практические предпосылки подготовки полилингвальных специалистов в вузе”, Могилев, с. 74-77.

Цеплякова А.Д., Іванова, С.Ф. (2010а), Лацінскія запазычанні крылатых слоў у сучаснай беларускай літаратурнай мове (колькасны склад, формы ўжывання $і$ крыніцы паходжання), "Веснік Мазырскага дзяржаўнага педагагічнага ўніверсітэта імя І.П. Шамякіна”, 1 (26), c. 88-93.

Цеплякова А.Д., Іванова С.Ф. (2010б), Старажытнагрэчаскія запазычанні крылатых слоў у сучаснай беларускай літаратурнай мове (колькасны склад, формы ўжывання і крыніиьы паходжання), “Веснік Полацкага дзяржаўнага ўніверсітэта”, серыя А, 7, с. 176-179.

Шулежкова С.Г. (2002), Крылатые выражения русского языка, их источники и развитие, Москва.

Шулежкова С.Г. (2013), От земли обетованной к небесам обетованным: очерки о судьбах библейских крылатых выражений, Москва.

Янкоўскі Ф. (1960), Крылатыя словы і афарызмы (з беларускіх літаратурных крыніи), Мінск.

Büchmann G. (1972), Geflügelte Worte. Der Zitatenschatz des deutschen Volkes, Berlin.

Ivanov E. (2016), Aphorism as a Unit of Language and Speech, "EUROPHRAS 2016: Word Combinations in the Linguistic System and Language Use: Theoretical, Methodological and Integrated Approaches", Trier, S. 42.

Tepljakowa A. (2019), Die deutschen Entlehnungen geflügelter Worte in der modernen belarussischen Schriftsprache, “Філологічний часопис Уманьского державного педагогічного університету імені Павла Тичини”, 1, 13, с. 122-129.

\section{Transkribierte Literatur}

Büchmann G. (1972), Geflügelte Worte. Der Zitatenschatz des deutschen Volkes, Berlin.

Cepljakova A.D. (2007), Struktura, semantyka i funkcyi zapazychanyh krylatyh slou u belaruskaj move "Slavjanskaja frazeologija v areal'nom, istoricheskom i etnokul'turnom aspektah", Gomel', ss. 236-240.

Cepljakova A.D. (2009a), Anglamounyja zapazychanni krylatyh slou u suchasnaj belaruskaj litaraturnaj move (kol'kasny sklad i krynicy pahodzhannja), "Vesnik Mazyrskaga dzjarzhaunaga pedagagichnaga universiteta imja I.P. Shamjakina", 2 (23), ss. 162-166.

Cepljakova A.D. (2009b), Njameckamounyja zapazychanni krylatyh slou u suchasnaj belaruskaj litaraturnaj move (kol'kasny sklad i krynicy pahodzhannja), "Vesnik Magiljouskaga dzjarzhaunaga universiteta imja A.A. Kuljashova”, 1 (32), ss. 137-143.

Cepljakova A.D. (2009v), Frankamounyja zapazychanni krylatyh slou u suchasnaj belaruskaj litaraturnaj move (kol'kasny sklad i krynicy pahodzhannja), "Vesnik Bresckaga dzjarzhaunaga universiteta imja A. S. Pushkina”, seryja filalagichnyh navuk, 2 (12), ss. 109-116. 
Cepljakova A.D. (2015), Inshamounyja zapazychanni krylatyh slou u suchasnaj belaruskaj move, "Teoreticheskie i prakticheskie predposylki podgotovki polilingval'nyh specialistov v vuze", Mogilev, ss. 74-77.

Cepljakova A.D., Ivanova, S.F. (2010a), Lacinskija zapazychanni krylatyh slou u suchasnaj belaruskaj litaraturnaj move (kol'kasny sklad, formy uzhyvannja i krynicy pahodzhannja), "Vesnik Mazyrskaga dzjarzhaunaga pedagagichnaga universiteta imja I.P. Shamjakina", 1 (26), ss. 88-93.

Cepljakova A.D., Ivanova S.F. (2010b), Starazhytnagrechaskija zapazychanni krylatyh slou u suchasnaj belaruskaj litaraturnaj move (kol'kasny sklad, formy uzhyvannja i krynicy pahodzhannja), "Vesnik Polackaga dzjarzhaunaga universiteta", seryja A, 7, ss. 176-179.

Djadechko L.P. (2002), Krylatyje slova kak ob'ekt lingvisticheskogo opisanija: istorija i sovremennost', Kiev.

Djadechko L.P. (2006), “Krylatyj slova zvuk”, ili Russkaja eptologija, Kiev.

Ivanov E.E. (2003), O rekkurentnyh prototipah krylatyh fraz, "Slavjanskaja frazeologija $v$ areal'nom, istoricheskom i etnokul 'turnom aspektah”, Gomel', ss. 74-78.

Ivanov E.E. (2007), Osnovnyje ponjatija kachestva lingvisticheskogo obrazovanija, "Vostochnoslavjanskie jazyki v evropejskom jazykovom kontekste", Mogilev, ss. 8-12.

Ivanov E.E. (2008), Kachestvo lingvisticheskogo obrazovanija v Respublike Belarus'(v aspekte mezhkul'turnoj kommunikacii), "Problemy kachestva obrazovanija v Belorussii i Rossii v kontekste integracionnyh processov", Moskva, 1, ss. 161-170.

Ivanov E. E. (2012), Obshchnost' zadach prepodavanija russkogo i inostrannyh jazykov belorusam (v aspekte mezhkul turnoj kommunikacii), "Vostochnoslavjanskie jazyki i literatury v evropejskom kontekste", Mogilev, ss. 3-7.

Ivanov E.E. (2013a), Belorusskaja paremiologija i aforistika vobshcheevropejskom kontekste (aktual'nyje problemy izuchenija), "XV Mizhnarodny z'ezd slavistau = XV Mezhdunarodnyj s'ezd slavistov $=$ XV International Congress of Slavists", Minsk, 1, ss. 322-333.

Ivanov E.E. (2013b), Belorusskaja paremiologija i aforistika vobshcheevropejskom kontekste (aktual'nyje problemy izuchenija), "Nationales und Internationales in der slawischen Praseologie", Greifswald, ss. 111-116.

Ivanov E. (2016), Aphorism as a Unit of Language and Speech, "EUROPHRAS 2016: Word Combinations in the Linguistic System and Language Use: Theoretical, Methodological and Integrated Approaches", Trier, S. 42.

Ivanov E.E. (2018), Problema ob’joma i differenciacii klassa vysshih (aforisticheskih) edinic jazyka (na materiale russkogo i belorusskogo jazykov), "Vostochnoslavjanskie jazyki i literatury v evropejskom kontekste - V”, Mogilev, ss. 28-32.

Ivanov E.E. (2000), Jazykovaja priroda krylatyh slov, "Prablemy belaruskaga litaraturaznaustva", Minsk, ss. 303-312.

Ivanov E.E., Ivanova S.F. (2012), Vostochnoslavjanskaja idiomatika v evropejskom jazykovom kontekste, "Itogi nauchnyh issledovanij uchenyh MGU im. A. A. Kuleshova", Mogilev, ss. 208-212.

Ivanou Ya.Ya. (2005), Krylatyja slovy, "Belaruski fal'klor": encyklapedyja”, Minsk, 1, ss. $729-730$.

Ivanou Ya.Ya. (2011), Krylatyja afaryzmy u belaruskaj move: z inshamounyh litaraturnyh i fal'klornyh krynic VIII st. da n. e. - XX st.: tlumachal'ny slounik, Magiljou. 
Ivanou Ya. Ya. (2014), Belaruskija prykazki z biblijnyh krynic (materyjaly da ruska-belaruskaanglijskaga slounika bibleizmau), "Avraamievskie chtenija”, Smolensk, ss. 11-24.

Ivanou Ya.Ya. (2016a), Universal'nae i nacyjanal'nae u frazealagichnaj i paremijalagichnaj padsistemah belaruskaj movy u eurapejskim mounym kanteksce (aktualnasc', metadalogija, perspektyvy dasledavannja), "Slavjanskaja frazeologija v sinhronii i diahronii", 3, ss. 46-49.

Ivanou Ya.Ya. (2016b), Frazealogija, paremijalogija, afarystyka belaruskaj movy i ih suvjazi $z$ inshymi movami jak napramak dasledavannjau navukovaj shkoly pa belaruskamu i agul'namu movaznaustvu u MDU imja A.A. Kuljashova (1995-2015), "Itogi nauchnyh issledovanij uchenyh MGU im. A.A. Kuleshova 2015 g.”, Mogilev, ss. 91-93.

Ivanou Ya.Ya. (2017a), Afarystychnae vykazvanne jak mounaja madel' krylatyh slou, "Filologichni studii”, 16, ss. 114-121.

Ivanou Ya.Ya. (2017b), Afarystychnyja adzinki u belaruskaj move, Magiljou.

Ivanou Ya.Ya., Cepljakova A.D. (2019), Litaraturnyja krynicy frazealagichnyh adzinak, zapazychanyh z njameckaj movy u belaruskuyu movu (pa-za mezhami etymalagichnaga slounika frazealagizmau, "Nemeckij jazyk lingvodidakticheskoe obespechenie i metodika prepodavanija", Mogilev, ss. 82-87.

Ivanou, Ya.Ya., Ivanova, S.F. (1997), Slounik belaruskih prykazak, prymavak i krylatyh vyrazau: lingvakrainaznauchy dapamozhnik, Minsk.

Lepeshau I.Ya. (1986), Krylatyja slovy, "Encyklapedyja litaratury i mastactva Belarusi", Minsk, 3, S. 137.

Lepeshau I.Ya. (1992), Krylatyja slovy i frazealagizmy, "Rodnae slova", 9, ss. 38-41.

Lomakina O.V., Mokienko V.M. (2019), Krylatika v sovremennom kul'turnom kontekste, "Vestnik Rossijskogo universiteta druzhby narodov", Serija: Teorija jazyka. Semiotika. Semantika, 10, 2, ss. 256-272.

Mihnevich A.Ya. (1994), Krylatyja slovy, "Belaruskaja mova: encyklapedyja”, Minsk, ss. 273-274.

Shulezhkova S.G. (2002), Krylatyje vyrazhenija russkogo jazyka, ih istochniki i razvitie, Moskva.

Shulezhkova S.G. (2013), Ot zemli obetovannoj k nebesam obetovannym: ocherki o sud'bah biblejskih krylatyh vyrazhenij, Moskva.

Tepljakova A.D. (2011a), Inojazychnyje zaimstvovanija krylatyh slov v belorusskom i nemeckom jazykah, "Jazyk, kul’tura, obshchestvo", Moskva, ss. 125-126.

Tepljakova A.D. (2011b), Istochniki krylatyh vyrazhenij v belorusskom jazyke, "Frazeologija i jazykovaja dinamika", Greifswald, Sankt-Peterburg, ss. 67-69.

Tepljakowa A. (2019), Die deutschen Entlehnungen geflügelter Worte in der modernen belare ussischen Schriftsprache, "Filologichnij chasopis Uman'skogo derzhavnogo pedagogichnogo universitetu imeni Pavla Tichini", 1, 13, ss. 122-129.

Venidziktau S.V. (2003), Inshamounyya krylatyja vyrazy u suchasnaj belaruskaj move, "Studia sławistyczne", 4, ss. 121-130.

Venidziktau S.V., Ivanou Ya.Ya. (2002), Ruskamounyja zapazychanni krylatyh slou u suchasnaj belaruskaj move, "Dziedzictwo przeszłości związków językowych, literackich i kulturowych polsko-bałto-wschodniosłowiańskich”, Białystok, VIII, ss. 210-217. 
Venidziktau S.V., Danilenka I.L., Ivanova S.F., Ivanou Ya.Ya. (2004), Krylatyja vyrazy u belaruskaj move. Chastka 1. Z inshamounyh (eurapejskih i amerykanskih) krynic XII-XX stst.: tlumachal'ny slounik, Magiljou.

Venidziktau S.V., Danilenka I.L., Ivanova S.F., Ivanou Ya.Ya., Cheh V.V. (2006), Krylatyja vyrazy u belaruskaj move. Chastka 2. Z ruskamounyh litaraturnyh i fal'klornyh krynic XIIXX stst. : tlumachal'ny slounik, Magiljou.

Yankouski F. (1960), Krylatyja slovy i afaryzmy (z belaruskih litaraturnyh krynic), Minsk.

\section{Abstract \\ About the structure of the dictionary of winged words in the modern literary German language (for Belarusians studying German as a foreign language)}

The article is devoted to the structural description of the dictionary of the winged words used in modern literary German language. It is suitable for Belarusians studying German as a foreign language. It shows texts as a source of winged words in the German language; principles of dictionary building, its scope, as well as examples of lexicographic descriptions of winged words as dated as the actual German sources themselves. Each and every German winged word in the dictionary has an equivalent in the Belarusian language. Therefore, the dictionary can be useful for Germans studying Belarusian as well.

Keywords: literary German language, literary Belarusian language, winged words, textual sources, dictionary.

\section{Streszczenie \\ O strukturze słownika skrzydlatych słów współczesnego języka niemieckiego (dla Białorusinów uczących się języka niemieckiego jako obcego)}

Artykuł poświęcony jest opisowi struktury słownika skrzydlatych słów powszechnie używanych we współczesnym języku niemieckim. Słownik adresowany jest do Białorusinów, którzy studiują język niemiecki jako obcy. Rozpatrywane są źródła tekstowe skrzydlatych słów w języku niemieckim, zasady konstruowania słownika, jego objętość, budowa hasła słownikowego oraz przytaczane są przykłady opisu leksykograficznego skrzydlatych wyrażeń o rodowodzie niemieckim. Każde niemieckie skrzydlate wyrażenie posiada odpowiednik białoruski, dlatego słownik może być przydatny również jako słownik przekładowy dla Niemców uczących się języka białoruskiego.

Słowa kluczowe: współczesny język niemiecki, współczesny język białoruski, skrzydlate słowa, źródła tekstowe, słownik

\section{Аннотация \\ О структуре словаря крылатых слов современного немецкого языка (для белорусов, изучающих немецкий язык как иностранный)}

Статья посвящена описанию структуры словаря употребительных крылатых выражений в современном немецком литературном языке. Словарь предназначен для белорусов, которые изучают немецкий язык как иностранный. Рассматриваются текстовые источники крылатых слов в немецком языке, принципы построения словаря, его объем, структура словарной статьи, а также приводятся примеры лексикографического описания крылатых выражений, восходящих к собственно немецким источникам. К каждому немецкому крылатому выражению в словаре приводится соответствие в белорусском языке. Поэтому словарь может быть полезен в качестве переводного также и немцам, изучающим белорусский язык.

Ключевые слова: современный немецкий язык, современный белорусский язык, крылатые слова, текстовые источники, словарь 